\title{
A thermodynamic study of the tantalum-oxygen system
}

by

\author{
Hyun Seon Hong*1 and Yeon Soo Kim ${ }^{2}$ \\ ${ }^{1}$ Department of Nuclear Engineering, University of California, Berkeley, CA 94720 \\ ${ }^{2}$ Argonne National Laboratory, Idaho Falls, ID 83403
}

\begin{abstract}
An evaluation of the partial thermodynamic functions of the tantalum-oxygen system (up to $\mathrm{O} / \mathrm{Ta}=2.5$ ) over the temperature range from $873 \mathrm{~K}$ to $3120 \mathrm{~K}$ is presented. The pressure-composition-temperature $(p-C-T)$ relationship in the single-phase region of solid Ta has been investigated. The relationships for other phases where no data were available from the literature have been proposed by using thermodynamic analysis. The results are presented as the oxygen isobars superimposed on the phase diagram.
\end{abstract}

Keywords: tantalum oxide, equilibrium oxygen pressure, phase diagram, thermodynamic constraints, analytical method

*Corresponding author. Tel: +1-510-642-7158, e-mail: hshong@nuc.berkeley.edu 


\section{Introduction}

Due to their high melting point and high resistance to many corrosive agents, tantalum and its alloy are becoming increasingly important as high-temperature structural materials. In addition, tantalum oxide is of great importance in the semiconductor industry and in the special optical glass for aerial lenses [1-3]. The mechanical and physical properties of tantalum and its oxide are greatly affected by the small amounts of impurity, especially by the gaseous elements such as oxygen, nitrogen, and hydrogen. Thermodynamic studies concerning the solution of gases up to the melting point of the solid phase and in the liquid phase would provide some useful information on the conditions both wherein the metals absorb gases and wherein the impurities can be removed.

The phase boundaries and thermodynamic properties for the tantalum-oxygen system were reviewed by Garg et al. $[2,3]$. However, the pressure-composition-temperature $(p-C$ $T$ ) relationships for each region of the system are considered to be insufficient.

Furthermore, the discrepancies among the thermodynamic functions available from the literature continue to be unresolved. Olander, Wang, Kim and Hong [4-11] have reviewed the $p-C-T$ relationships of some oxides such as $\mathrm{V}-\mathrm{O}, \mathrm{Ti}-\mathrm{O}, \mathrm{U}-\mathrm{O}, \mathrm{Y}-\mathrm{O}$ and $\mathrm{Zr}-\mathrm{O}$ systems and some nitrides such as $\mathrm{V}-\mathrm{N}, \mathrm{Zr}-\mathrm{N}$ and Ti-N. The goal of the present work is to extend the serial thermodynamic analysis work by the authors to the Ta-O system. The methods that the authors developed have been satisfactorily applied to the analysis of various $\mathrm{M}-\mathrm{X}(\mathrm{M}=\mathrm{U}, \mathrm{Zr}, \mathrm{Ti}, \mathrm{Y}, \mathrm{V}$, and $\mathrm{X}=\mathrm{O}, \mathrm{H}, \mathrm{N})$ systems [4-11]. In the present study, 
most of the inconsistencies in the tantalum-oxygen system are critically reviewed and are resolved using the technique outlined in the following section.

\section{Analysis methods}

\subsection{Thermodynamic constraints}

When pure tantalum, either solid or liquid, is exposed to oxygen gas, a homogeneous tantalum-oxygen solution is formed. The reaction can be represented by

$T a_{(s, L)}+\frac{C}{2} O_{2(g)}=T a O_{C}$

where $C$ is the oxygen-to-tantalum atom ratio. It can be shown [12] that the relative integral free energy of the formation of $\mathrm{TaO}_{\mathrm{C}}$ is related to the relative partial molar free energies of oxygen $\left(\Delta \bar{G}\left(O_{2}\right)=R T \ln p\right)$ over the entire $\mathrm{O} /$ Ta range by

$\Delta \mathrm{G}_{\mathrm{f}}^{0}\left(\mathrm{TaO}_{\mathrm{C}}\right)=\frac{R T}{2} \int_{0}^{C} \ln p d C^{\prime}$

where $p$, a function of $C$ and $T$, is the equilibrium oxygen pressure of the oxide. Pure tantalum has been chosen as the standard state for the oxide. $0.1 \mathrm{MPa} O_{2}$ is the reference standard state of the relative partial molar energies in Eq. (2). 
2.2. Continuity requirements

Speiser [13] showed that the coexistence of three solid phases at the eutectic of metalhydrogen systems requires the three-phase equilibrium to be interrelated. If this requirement is applied to the eutectic point of the Ta-O system at $T=2153 \mathrm{~K}$ shown in Fig. 1, it is interpreted as follows:

$\left[C_{L 2(e)}-C_{T a(e)}\right] \Delta \bar{H}_{T a+L 2}=\left[C_{L 1(e)}-C_{T a(e)}\right] \Delta \bar{H}_{T a+L 1}+\left[C_{L 2(e)}-C_{L 1(e)}\right] \Delta \bar{H}_{L 1+L 2}$

where $\mathrm{C}_{\mathrm{Ta}(\mathrm{e})}(=0.06), \mathrm{C}_{\mathrm{L} 1(\mathrm{e})}(=0.75)$ and $\mathrm{C}_{\mathrm{L} 2(\mathrm{e})}(=1.86)$ are the eutectic oxygen

concentrations, $\Delta \bar{H}$ is the relative partial molar enthalpy and the subscripts indicate the corresponding two-phase regions.

The coexistence of three phases at the eutectic temperature also implies that the equilibrium pressures for the three two-phases must satisfy the following equalities:

$\ln P_{T a+L 2}\left(T_{e}\right)=\ln P_{T a+L 1}\left(T_{e}\right)=\ln P_{L 1+L 2}\left(T_{e}\right)$

where $T_{e}$ is the eutectic temperature.

Thus, if two of the $p-C-T$ relationships are known for the two-phase regions, the information for the third one can be fixed from Eqs. (3) and (4). 


\subsection{Sieverts law}

If Sieverts law behavior is assumed for oxygen dissolution up to the terminal

solubility in Ta, then the corresponding equilibrium, $\frac{1}{2} O_{2(g)}=O_{\text {diss. }}$, yields the following mass action law:

$\frac{C}{\sqrt{p_{T a}}}=\frac{C_{s}}{\sqrt{p_{T a+T a_{2} \mathrm{O}_{s}}}}=K_{s}$

where $C_{s}\left(=C_{T_{a} / T a_{2} O_{5}}\right.$, the phase boundary between $\mathrm{Ta}$ and $\mathrm{Ta}^{2}+\mathrm{Ta}_{2} \mathrm{O}_{5}$ in Fig. 1) is the terminal solubility of oxygen in the tantalum metal, $p_{T a}$ and $p_{T a+T a_{2} O_{s}}$ are the equilibrium pressures of molecular oxygen $\left(\mathrm{O}_{2}\right)$ over the Ta and two-phase $\mathrm{Ta}+\mathrm{Ta}_{2} \mathrm{O}_{5}$ regions, respectively, and $K_{\mathrm{s}}$ is the corresponding Sieverts law constant.

A detailed discussion of the correlation similar to Eq. (5) can be found elsewhere [89]. When applied to a real situation, Eq. (5) provides a relationship between the equilibrium pressures over $\mathrm{Ta}$ and $\mathrm{Ta}+\mathrm{Ta}_{2} \mathrm{O}_{5}$ and $K_{\mathrm{s}}$, which are usually measured independently. By rearranging Eq. (5), $p_{T a}$ can be expressed as follows:

$\ln p_{T a}=\ln p_{T a+T a_{2} O_{5}}+2 \ln \frac{C}{C_{T a / T a_{2} O_{5}}}$ 
Eq. (6) is usually valid for a dilute solution and useful to derive the $p-C-T$ relationship of the single phase where that of the adjacent two-phase region is known, and vice versa.

\subsection{Applications}

The integral constraint given by Eq. (2) is applied to validate the $p-C$ - $T$ relationships established over the regions of $\mathrm{Ta}$ and $\mathrm{Ta}+\alpha \mathrm{Ta}_{2} \mathrm{O}_{5}$. Eqs. (3) and (4) are used to obtain the $p-C-T$ relationship in the $\mathrm{L} 1$ phase where no measurement data are found in the literature. The Sieverts law assumption in Eq. (5) is utilized to calculate the $p-C-T$ relationship over the two-phase region, $\mathrm{Ta}+\alpha \mathrm{Ta}_{2} \mathrm{O}_{5}$, being combined with the Gibbs energy of solution of oxygen in Ta. Eq. (6) is used to establish the $p-C-T$ relationship over the regions of $\mathrm{Ta}+\mathrm{L} 1$ and $\mathrm{Ta}+\alpha \mathrm{Ta}_{2} \mathrm{O}_{5}$.

\section{The tantalum-oxygen system}

The phase diagram of the Ta-O system, as shown in Fig. 1, is retrieved from Garg et al. [2,3]. All of the corresponding phase boundaries used in this study are listed in Table 1. Similar to other transition metal-oxygen systems, available data for the equilibrium oxygen potentials over the phase regions of the Ta-O system are scant. In this section, experimental databases available from the literature will be systematically examined with the proposed methods discussed in the previous section. 
3.1. Solid Ta region, $873 \mathrm{~K}<\mathrm{T}<3120 \mathrm{~K}$

The $p-C-T$ relationship for the single-phase Ta has been investigated in the temperature range 873-3120 K [14-18]. Fromm and Kirchheim [14] reported a $p-C-T$ relationship for the single-phase region, in the temperature range $873-1373 \mathrm{~K}$ as follows:

$\ln p_{T a}=2 \ln \frac{C}{C+1}+23.03-\frac{9.25 \times 10^{4}}{T}$

where $p$ is the equilibrium oxygen pressure in bar, $C$ the oxygen-to-tantalum atom ratio, and $T$ temperature in Kelvin.

Recently, Lee and Alstetter [15] suggested a similar relationship for the same temperature range,

$\ln p_{T a}=2 \ln \frac{C}{C+1}+23.64-\frac{9.34 \times 10^{4}}{T}$.

Some studies were conducted on the $p-C-T$ relationship at higher temperatures. Fromm and Jehn [16] proposed the following $p$-C-T relationship for temperatures between $2273 \mathrm{~K}$ and $2723 \mathrm{~K}$,

$\ln p_{T a}=\ln \frac{C}{C+1}-4.17-\frac{3.44 \times 10^{4}}{T}$. 
Schulze, Jehn and Grallath [17] suggested the $p-C-T$ relationship for temperatures between $2270 \mathrm{~K}$ and $2770 \mathrm{~K}$,

$\ln p_{T a}=\ln \frac{C}{C+1}+15.81-\frac{6.74 \times 10^{4}}{T}$

Pemsler [18] measured the oxygen concentration in the tantalum single phase as a function of pressure at temperatures near the melting point that is in equilibrium with the pure gas. As a result, he reported the equilibrium pressure of oxygen over tantalum containing 0.3 at $\%$ oxygen $(C=0.003)$ in the temperature range $2660-3120 \mathrm{~K}$ :

$\ln p_{T a}=13.4-\frac{6.22 \times 10^{4}}{T}$

It is to be noted that Eqs. (7) and (8) are applicable for a lower temperature range whereas Eqs. (9) - (11) are applicable for a higher temperature range ( > $2200 \mathrm{~K}$ ). Fig. 2 compares the databases investigated in this section. In Fig. 2(a), the oxygen partial pressures (in $\ln p_{T a}$ ) from Eqs. (7) - (10) are plotted at $\mathrm{C}=0.003$ as a function of temperature to compare with Pemsler's data. It can be seen that data of Fromm and Kirchheim (Eq. (7)) are virtually identical to those of Lee and Alstetter (Eq. (8)). From this, Eqs. (7) and (8) are considered to be reliable and can be used for representing the single-phase Ta. However, data from Fromm, Schulze and Pemsler (Eqs. (9)-(11)) applicable at higher temperature $(>2200 \mathrm{~K})$ are not in a good agreement. In order to 
compare these equations with Eqs. (7) and (8), the lines from Eqs. (7) and (8) are extrapolated to higher temperatures in Fig 2(a). It can be seen that Eq. (11) of Pemsler's data is much higher than Eqs. (7) and (8). However, Eqs. (9) and (10) are close to Eqs. (7) and (8). It is noticed that Eq. (10) is more consistent to Eq. (7) and Eq. (8) than Eq. (9). Fig. 2(b) represents the oxygen pressures at $C=C_{s}$ as a function of temperature. The shape of the graphs is the same as that of Fig. 2(a) except that the crossover temperature between two lines from Fromm and Schulze [Eq. (9-10)] decreased from that of Fig. 2(a). Consequently, it is considered that both of Eq. (7) and Eq. (8) are eligible to represent the single-phase Ta for the temperature range 873-1373 K. For simplicity, Eq. (7) is selected to calculate $\Delta \mathrm{G}_{\mathrm{f}}^{0}$ given in Eq. (2) and to construct the oxygen isobars for the present study. In addition, Eq. (10) can be chosen for the temperature range 2273-3120 K.

\subsection{Ta-O solid solution}

The free energies of the Ta-O solid solution have been investigated by Garg [2], Lee and Altstetter [15], Fromm [19], and Nickerson and Altstetter [20]. According to Garg [2], oxygen in tantalum obeys Henry's law in the entire solid solution range between $1000 \mathrm{~K}$ and $1600 \mathrm{~K}$. Garg reported the standard free energy change

$\Delta \mathrm{G}^{0}=-398.8+7.788 \times 10^{-2} T-3.488 T \log T-2.853 \times 10^{-6} T^{2} \quad(\mathrm{~kJ} / \mathrm{mol})$

for the reaction

$1 / 2 O_{2}(g) \rightarrow O($ solid solution $)$. 
Fromm [19] reported the following equation for the temperature range of 1000-3000 K,

$$
\Delta \mathrm{G}^{0}=-373+8.9 \times 10^{-2} T \quad(\mathrm{~kJ} / \mathrm{mol})
$$

Nickerson and Altstetter [20] reported the following equation based on the work by Worrell [21] in the temperature range $1123-1573 \mathrm{~K}$ :

$$
\Delta \mathrm{G}^{0}=-389+6.2 \times 10^{-2} T(\mathrm{~kJ} / \mathrm{mol})
$$

Lee and Altstetter [15] expanded the data given by Nickerson and Altstetter to make them applicable to a wider temperature range, namely, 1000-3000 K. Their result was given by

$$
\Delta \mathrm{G}^{0}=-388+6.0 \times 10^{-2} T \quad(\mathrm{~kJ} / \mathrm{mol})
$$

Fig. 3 compares Eqs. (12), (14)-(16). It can be seen that three databases of Lee, Garg, and Nickerson are fairly close among themselves while Fromm's data (Eq. (14)) exhibit much higher than the others. Especially, Eqs. (15) and (16) are almost identical although Eq. (16) covers a wider temperature range. Thus, Eq. (16) is preferred for the free energy of dissolution and used to obtain a $p-C-T$ relationship for the $\mathrm{Ta}^{-} \mathrm{Ta}_{2} \mathrm{O}_{5}$ phase discussed in Sect. 3.3. 
The Gibbs energy of solution of oxygen dissolution in solid tantalum (defined as $-R T \ln K_{s}$ ) is compared with other metal-oxygen systems in Fig. 4. The enthalpy of oxygen dissolution in solid tantalum from the above equation $(-398 \mathrm{~kJ} / \mathrm{mol}-\mathrm{K})$ is closer to those of Zr-O (-466 kJ/mol-K), U-O (445 kJ/mol-K) and V-O (472 kJ/mol-K) systems $[8,10,11]$. However, it is different from those of Ti-O $(609 \mathrm{~kJ} / \mathrm{mol}-\mathrm{K})$ and $\mathrm{Y}-\mathrm{O}(576$ $\mathrm{kJ} / \mathrm{mol}-\mathrm{K})$ systems $[4,9]$ particularly at low temperatures. It can also be seen in Fig. 4 that the entropy of oxygen dissolution in tantalum in Eq. (16) is similar to those of U-O and $\mathrm{Zr}-\mathrm{O}$ systems but less positive than those of Ti-O and V-O system.

3.3. Solid $\mathrm{Ta}+\mathrm{Ta}_{2} \mathrm{O}_{5}$ region, $873 \mathrm{~K}<\mathrm{T}<2153 \mathrm{~K}$

No data for the equilibrium oxygen pressure over the $\mathrm{Ta}^{+} \mathrm{Ta}_{2} \mathrm{O}_{5}$ phase, $p_{T+\mathrm{Ta}_{2} \mathrm{O}_{5}}$, is available in the literature. However, $p_{T a+T a_{2} O_{5}}$ can be obtained by extrapolating Eq. (7) and Eq. (8) to the upper-phase boundary of Ta, where it equals that of the two-phase $\mathrm{Ta}+\mathrm{Ta}_{2} \mathrm{O}_{5}$. Using this method, we obtain from Eq. (7)

$\ln p_{T+\mathrm{Ta}_{2} \mathrm{O}_{5}}=18.97-\frac{9.65 \times 10^{4}}{T}$,

and from Eq. (8)

$\ln p_{T_{a+T a_{2} O_{5}}}=19.58-\frac{9.72 \times 10^{4}}{T}$.

This extrapolation method has been applied successfully in many metal-gas systems [4-11]. The equilibrium oxygen pressure over the $\mathrm{Ta}+\mathrm{Ta}_{2} \mathrm{O}_{5}$ phase can be also derived from the Gibbs energy of oxygen solution in Ta. 
Since the Gibbs energy of solid solution is defined as $-R T \ln K_{s}[22], \ln p_{T a+T a_{2} O_{5}}$ can be calculated by combining Eq. (6) and Eq. (16). We obtain

$\ln p_{T_{a+T a_{2} O_{5}}}=19.89-\frac{9.54 \times 10^{4}}{T}$

Eq. (19) is consistent with Eqs. (17) and (18). The validity of the $p-C-T$ relationships established in this section will be further evaluated by applying the integral constraint given in Eq. (2) in the sect. 3.6.

\section{4. $\mathrm{Ta}+\mathrm{L} 1$ region}

The pressure-composition-temperature $(p-C-T)$ relationship in the Ta region for the temperature range $2273-2723 \mathrm{~K}$ is given by Eqs. (9) and (10) in the section 3.1. Parallel to the case in the two-phase region of $\mathrm{Ta}+\mathrm{Ta}_{2} \mathrm{O}_{5}$ [Eqs. (17) and (18)], $p_{T a+L 1}$ can be obtained by extrapolating Eqs. (9) and (10) to the lower phase boundary of Ta+L1.

From Eq. (9),

$\ln p_{T a+L 1}=-12.21-\frac{2.29 \times 10^{4}}{T}$

From Eq. (10),

$\ln p_{T a+L 1}=-7.78-\frac{5.59 \times 10^{4}}{T}$. 
These two values show a slight discrepancy. However, Eq. (20) is selected to calculate $\ln p_{L 1+L 2}$ in the following section because Eq. (9) is consistent with Eqs. (7) and (8) at higher temperatures than $2200 \mathrm{~K}$.

\section{5. $\mathrm{L} 1$ and $\mathrm{L} 1+\mathrm{L} 2$ regions}

There is no equilibrium oxygen pressure datum for $\mathrm{L} 1$ and $\mathrm{L} 1+\mathrm{L} 2$ regions available in the literature. However, a $p-C-T$ relationship for $\mathrm{L} 1$ phase can be estimated by using the enthalpy continuity requirement discussed Section 2.2. The enthalpy term $\Delta \bar{H}_{\mathrm{L} 1+\mathrm{L} 2}(=1167.83 \mathrm{~kJ} / \mathrm{mol})$ is calculated applying Eq. (3) with $\Delta \bar{H}_{\mathrm{Ta}+\mathrm{L} 1}(=190.39 \mathrm{~kJ} / \mathrm{mol})$ from Eq. $(20)$ and $\Delta \bar{H}_{\mathrm{Ta}+\mathrm{Ta}_{2} \mathrm{O}_{5}}(=793.16 \mathrm{~kJ} / \mathrm{mol})$ from Eq. (19) at $\mathrm{T}=2153 \mathrm{~K}$. The entropy term is fixed using the pressure continuity requirement given in Eq. (4) and $\Delta \bar{H}_{\mathrm{L} 1+\mathrm{L} 2}$ obtained above at $\mathrm{T}=2153 \mathrm{~K}$. The $p-C-T$ relationship derived by this method is

$\ln p_{L 1+L 2}=-40.19-\frac{14.04 \times 10^{4}}{T}$.

Fig. 5 demonstrates the good agreement of the equilibrium pressure of the three twophases at $\mathrm{T}=2135 \mathrm{~K}$. This confirms that the consistency between the $p-C-T$ relationships of the three two-phase are related to the eutectic. 
Investigation of the partial thermodynamic functions of solid solution bounded by two-phase regions has been the subject of many studies [23-25], which all suggest that a linear interpolation is a good approximation for a narrow region. The equilibrium oxygen pressure for the L1 phase is approximated by using this method.

$$
\begin{gathered}
\ln p_{L 1}=\ln p_{L 1+L 2}+\left(\frac{C-C_{(L 1+L 2) / L 1}}{C_{(T a+L 1) / L 1}-C_{(L 1+L 2) / L 1}}\right) \times\left(\ln p_{T a+L 1}-\ln p_{L 1+L 2}\right) \\
\quad \text { for }\left(\mathrm{C}_{(T a+L 1) / L 1} \leq \mathrm{C} \leq \mathrm{C}_{(L 1+L 2) / L 2}\right)
\end{gathered}
$$

\subsection{Evaluation of $\Delta \mathrm{G}_{\mathrm{f}}^{\mathrm{o}}\left(\mathrm{Ta}_{2} \mathrm{O}_{5}\right)$}

The validity of the $p-C-T$ relationships established in the previous sections are examined by applying the integral constraint Eq. (2) at temperatures between 873 and 1373 K. In this range, Eq. (2) can be rearranged as follows:

$$
\Delta \mathrm{G}_{\mathrm{f}}^{\mathrm{o}}\left(T a_{2} O_{5}\right)=R T\left(\int_{0}^{\mathrm{C}_{T a / \mathrm{Ta} \mathrm{O}_{5}}} \ln p_{T a} d \mathrm{C}^{\prime}+\int_{\mathrm{C}_{T a / \mathrm{T}{ }_{2} \mathrm{O}_{5}}}^{2.5} \ln p_{T a+T a_{2} O_{5}} d \mathrm{C}^{\prime}\right)
$$

where $\Delta \mathrm{G}_{\mathrm{f}}^{\mathrm{o}}\left(\mathrm{Ta}_{2} \mathrm{O}_{5}\right)$ is the integral Gibbs free energy of $\mathrm{Ta}_{2} \mathrm{O}_{5}$ and $C_{\mathrm{Ta} / \mathrm{Ta}_{2} \mathrm{O}_{5}}$ the phase boundary between $\mathrm{Ta}$ and $\mathrm{Ta}_{2} \mathrm{O}_{5}$ shown in Fig. 1 .

Integration of the right hand side of Eq. (24) is carried out with the database of Fromm and Kirchheim (Eqs. (7) and (17)) to yield 


$$
\Delta \mathrm{G}_{\mathrm{f}}^{0}\left(\mathrm{Ta}_{2} \mathrm{O}_{5}\right)=-2013.33+0.40 T \mathrm{~kJ} / \mathrm{mole} .
$$

When the databases of Lee and Altstetter (Eqs. (8) and (18)) are used, the integration results in,

$$
\Delta \mathrm{G}_{\mathrm{f}}^{0}\left(\mathrm{Ta}_{2} \mathrm{O}_{5}\right)=-2019.67+0.41 T
$$

Experimental determination of the Gibbs free energy of formation of the tantalum oxide, $\Delta \mathrm{G}_{\mathrm{f}}^{0}\left(\mathrm{Ta}_{2} \mathrm{O}_{5}\right)$, was carried out using the galvanic cell technique by Ignatowicz and Davies [26]. Their data was expressed in the temperature range 1073-1373 K as

$$
\Delta \mathrm{G}_{\mathrm{f}}^{0}\left(\mathrm{Ta}_{2} \mathrm{O}_{5}\right)=-2016.4+0.405 T \mathrm{~kJ} / \mathrm{mole},
$$

They claimed that the measured data agreed very well with those obtained by Coughlin [27] from calorimetric measurements and reasonably well with Worrell [20]. Rezukhina and Kravchenko [28] also used the galvanic cell technique to obtain

$$
\Delta \mathrm{G}_{\mathrm{f}}^{0}\left(\mathrm{Ta}_{2} \mathrm{O}_{5}\right)=-2020.6+0.414 T \mathrm{~kJ} / \mathrm{mole},
$$

in the temperature range $1200-1350 \mathrm{~K}$.

Wicks and Block [29] measured calorimetrically to give 


$$
\Delta \mathrm{G}_{\mathrm{f}}^{0}\left(\mathrm{Ta}_{2} \mathrm{O}_{5}\right)=-2018.9+0.415 T \mathrm{~kJ} / \mathrm{mole},
$$

for the temperature range 1200-1350 K. It was considered that the values given in Eq. (28) were in almost perfect agreement with Eq. (29). Recently, Kubaschewski [12] suggested the value of

$$
\Delta \mathrm{G}_{\mathrm{f}}^{0}\left(\mathrm{Ta}_{2} \mathrm{O}_{5}\right)=-2062.2+0.7 T-0.09 T \log T
$$

Chase et al. [30] reviewed works by Ignatowicz and Davies [26], Rezukhina and Kravchenko [28], Worrell [20] and Barbi [31] and tabulated recommendable values as a function of temperature by using the least-squares method. Based on the work by Chase, Garg et al. [2,3] later provided an expression for $\Delta \mathrm{G}_{\mathrm{f}}^{0}\left(\mathrm{Ta}_{2} \mathrm{O}_{5}\right)$ applicable to the wide range of $298-2145 \mathrm{~K}$,

$\Delta \mathrm{G}_{\mathrm{f}}^{0}\left(\mathrm{Ta}_{2} \mathrm{O}_{5}\right)=-2048+0.509 T-0.0174 T \log T-1.426 \times 10^{-5} T^{2}$.

A comparison between values calculated from Eqs. (25) and (26) and measurement data of $\Delta \mathrm{G}_{\mathrm{f}}^{0}\left(\mathrm{Ta}_{2} \mathrm{O}_{5}\right)$ from the literature (Eqs. (27)-(31)) is shown in Fig. 6. A narrower than the actual temperature range for the equations is used in the graph to allow a closeup view for a comparison.

It can be seen that all values are fairly consistent and fall between Garg's and Kubaschewski's data. In addition, the database of Fromm and Kirchheim [13] has been 
shown to be the one that is most consistent with that of Garg [2] and Rezukhina [28], whereas the database of Lee and Altstetter is closest to that of wicks and Block [29].

From the above result, it is considered that the calculated $\Delta \mathrm{G}_{\mathrm{f}}^{0}\left(\mathrm{Ta}_{2} \mathrm{O}_{5}\right)$ given in Eqs. (25) and (26) are not only consistent among themselves, but also agree well with the independently measured values given in Eqs. (27)-(31). This confirms that the method used to obtain the $p-C-T$ relationship for the two phase $\mathrm{Ta}+\mathrm{Ta}_{2} \mathrm{O}_{5}$ is valid.

3.7. Oxygen isobars and analysis uncertainties

The $p-C-T$ relationships of oxygen in equilibrium with the Ta-O system from pure tantalum to tantalum pentaoxide [Eq. (7), (10), (17), (20) and (22)] are used to construct the oxygen isobars superimposed on the phase diagram shown in Fig. 1. The isobars match very well at all phase boundaries.

The $p-C-T$ relationships proposed in the literature are insufficient, especially at temperatures higher than $2200 \mathrm{~K}$. In this context, uncertainties could be expected although the scheme of the present study is supported by valid thermodynamic constraints. These uncertainties can only be resolved when further experimental data are available. 


\section{Conclusion}

The $p-C-T$ relationships of the Ta-O system have either been examined or generated by using the proposed thermodynamic constraints and the Sieverts law. The discrepancies among the databases obtained from the literature have been critically reviewed. In addition, satisfactory $p-C-T$ relations have been developed for regions where no experimental data were available. The developed $p-C-T$ relationships were validated by applying the integral constraint of Eq. (2). The Gibbs energy of solution for oxygen dissolution in solid tantalum has also been obtained. 


\section{References}

[1] V.A. Gubanov, A.L. Ivanovsky, and V.P. Zhukov, in Electronic Structure of refractory Carbides and Nitrides, Cambridge University Press, 1994.

[2] S. P. Garg, N. Krishnamurthy, A. Awasthi, and M. Venkatraman, The O-Ta (oxygentantalum) system, J. Phase Equil., 17 (1996) 63.

[3] S. P. Garg, N. Krishnamurthy, A. Awasthi, and M. Venkatraman, The O-Ta (oxygentantalum) system, J. Phase Equil., 18 (1997) 407.

[4] Wei-E Wang and Yeon Soo Kim, A thermodynamic evaluation of the titanium oxygen system from $\mathrm{O} / \mathrm{Ti}=0$ to 3/2, J. Nucl. Mater., 270 (1999) 242.

[5] Wei-E Wang, Yeon Soo Kim, and Hyun Seon Hong, Characterization of the Vanadium-Nitrogen System with Nitrogen Pressure Isobars, J. Alloys Comp., 308 (2000) 147.

[6] Wei-E Wang and D. R. Olander, Computational thermodynamics of the Zr-N system, J. Alloys Comp., 224 (1995) 153.

[7] Wei-E Wang, Partial thermodynamic properties of the titanium-nitrogen system, J. Alloys Comp., 233 (1996) 89.

[8] Wei-E Wang and D. R. Olander, Thermochemistry of the U-O and Zr-O systems, J. Amer. Ceram. Soc., 75 (1993) 1242.

[9] Wei-E Wang and D. R. Olander, Characterization of the Phase Diagram of YttriumOxygen System with Oxygen Isobars, High Temp. Mater. Sci., 37 (1997) 13.

[10] Yeon Soo Kim, A thermodynamic evaluation of the $\mathrm{U}-\mathrm{O}$ system from $\mathrm{UO}_{2}$ to $\mathrm{U}_{3} \mathrm{O}_{8}$, J. Nucl. Mater., 279 (2000) 173. 
[11] Yeon Soo Kim, V-O thermochemostry from the pure meal to monoxide, J. Alloys Comp., 312 (2000) 86.

[12] O. Kubaschewski, in Metallurgical Thermochemistry, 5th Ed., Pergamon Press, 1979.

[13] T. R. Speiser, The thermodynamics of metal-hydride system, W. M. Mueller, J. P. Blackledge and G.G. Libowitz (eds.), Metal Hydrides, Academic Press, New York, 1968, P.81.

[14] E. Fromm, R. Kirchheim, EMF-measurements in oxygen-VA metals systems using a $\mathrm{ThO}_{2}-\mathrm{Y}_{2} \mathrm{O}_{3}$ solid electrolyte, Z. Metallkd., 66 (1975) 144.

[15] J. S. Lee, and C. J. Altstetter, Thermodynamics studies of oxygen behavior in tantalum based alloys, Acta Metall., 34 (1986) 139.

[16] E. Fromm, and H. Jehn, Steady states during annealing niobium and tantalum in oxygen, Z. Metallkd., 58 (1967) 61.

[17] K. Schulze, H. Jehn, and E. Grallath, Steady-state oxygen-solubility in tantalum, $Z$ Metallkd., 70 (1979) 625.

[18] J. P. Pemsler, Thermodynamics of the interaction of Niobium and tantalum with oxygen and nitrogen at temperatures near the melting point, J. Elecrochem. Soc. 108 (1961) 144.

[19] E. Fromm, Thermodynamic calculations in alpha-solid solution area of systems NbC, Nb-N, Nb-O, Nb-C-O, Ta-C, Ta-N, Ta-O and Ta-C-O”, J. Less Common Metals, 14 (1968) 113.

[20] W. Nickerson and C. Altstetter, Thermodynamic properties of tantalum-oxygen solid solution, Scripta Metall., 7 (1973) 377. 
[21] W. Worrell, Thermodynamics, Vol. 1, IAEA, Vienna, 131 (1966).

[22] Y. A. Chang, K. Fitzner, and M. X. Zhang, The solubility of gases in liquid-metals and alloys, Prog. Mater. Sci. 32 (1988) 97.

[23] P. Dantzer, W. Luo, T.B. Flanagan, and J. D. Clewley, Calorimetrically measured enthalpies for the reaction of $\mathrm{H}_{2}$ with $\mathrm{Zr}$ and $\mathrm{Zr}$ alloys, Metall. Trans., A 24 (1993) 471.

[24] P. Dantzer, High temperature thermodynamics of $\mathrm{H}_{2}$ and $\mathrm{D}_{2}$ in titanium and in dilute titanium oxygen solid solutions, J. Phys. Chem. Solid, 44 (1983) 913.

[25] G. Boureau and P. Gerdanian, High temperature thermodynamics of oxygen in zirconium and hafnium, Phys. Chem. Solids. 45 (1984) 141.

[26] S. Ignatowicz and M. W. Davies, Free energy of $\mathrm{NbO}$ and $\mathrm{Ta}_{2} \mathrm{O}_{5}$, J. Less-Common Metals, 15 (1968) 100.

[27] J. P. Coughlin, U. S. Bureau Mines Bull. 542 (1954).

[28] T. N. Rezukhina and L. I. Kravchenko, Thermodynamic properties of laves phases in mixtures of Ta $+\mathrm{CO}$ solid electroyte galvanic cell studies, J. Chem. Thermodyn. 4 (1972) 655.

[29] C. Wicks and F. Block, U. S. Bureau Mines Bull. 605 (1963).

[30] M. W. Chase, Jr., C. A. Daies, J. R. Downey D. J. Frurip, R. A. McDonald and A. N. Syverud, JANAF Thermochemical Tables, Third Edition, Part 2, Cr-Zr, Am. Chem. Soc., American Institute of Physics and national Bureau of Standards, New York (1986).

[31] G. B. Barbi, Electrochemical determination o free energy of formation of tantalum oxide, Z. Naturforsch, 254 (1970) 1515. 
Table 1: The composition-temperature relationships of the phase boundaries $\mathrm{C}_{\mathrm{i}}$ (shown in Fig.1) expressed as $\mathrm{C}_{\mathrm{i}}=\mathrm{a}+\mathrm{bT}+\mathrm{dT}^{2}$, where $\mathrm{T}$ in $\mathrm{K}$.

\begin{tabular}{|c|c|c|c|}
\hline \hline $\mathrm{C}_{\mathrm{i}}$ & $\mathrm{a}$ & $\mathrm{b}$ & $\mathrm{d}$ \\
\hline $\mathrm{C}_{\mathrm{Ta} / \beta *}$ & -0.01829 & $3.659 \times 10^{-5}$ & 0 \\
\hline $\mathrm{C}_{\mathrm{Ta} / \alpha *}$ & -0.02927 & $4.348 \times 10^{-5}$ & 0 \\
\hline $\mathrm{C}_{\mathrm{Ta} / \mathrm{Ta}+\mathrm{L} 2}$ & -0.01688 & $3.571 \times 10^{-5}$ & 0 \\
\hline $\mathrm{C}_{\mathrm{Ta}+\mathrm{L} 2 / \mathrm{L} 2}$ & 5.71 & $-1.79 \times 10^{-3}$ & 0 \\
\hline $\mathrm{C}_{\mathrm{L} 2 / \alpha}$ & 2.18 & $1.50 \times 10^{-4}$ & 0 \\
\hline $\mathrm{C}_{\mathrm{Ta} / \mathrm{Ta}+\mathrm{L} 1}$ & 0.35 & $-1.89 \times 10^{-4}$ & $2.52 \times 10^{-8}$ \\
\hline $\mathrm{C}_{\mathrm{Ta}+\mathrm{L} 1 / \mathrm{L} 1}$ & 2.14 & $-6.89 \times 10^{-4}$ & $1.45 \times 10^{-8}$ \\
\hline $\mathrm{C}_{\mathrm{L} 1 / \mathrm{L} 1+\mathrm{L} 2}$ & 0.487 & $1.22 \times 10^{-4}$ & 0 \\
\hline $\mathrm{C}_{\mathrm{L} 1+\mathrm{L} 2 / \mathrm{L} 2}$ & 3.29 & $-6.65 \times 10^{-4}$ & 0 \\
\hline \hline
\end{tabular}

*; $\beta=\beta-\mathrm{Ta}_{2} \mathrm{O}_{5}$, and $\alpha=\alpha-\mathrm{Ta}_{2} \mathrm{O}_{5}$ 


\section{Figure captions}

Fig. 1 Revised phase diagram of the Ta-O system [2,3]. Oxygen isobars are indicated by the index $\mathrm{k}$ in $\mathrm{p}\left(\mathrm{O}_{2}\right)=10^{-\mathrm{k}}$ bar.

Fig. 2 Comparison of $\ln P(\mathrm{Ta})$ obtained from the literature.

(a) oxygen pressure at $0.3 \mathrm{at} \% \mathrm{O}$ concentration

(b) oxygen pressure at the terminal solubility $\left(\mathrm{C}_{\mathrm{s}}\right)$

Fig. 3 Gibbs free energy of dissolution from Eq. (12) to Eq. (15).

Fig. 4 Gibbs energy of oxygen dissolution in the metals obtained from the literature.

Fig. 5 Equilibrium oxygen pressures over the univariant two-phase regions $\left(\mathrm{Ta}^{+}+\mathrm{Ta}_{2} \mathrm{O}_{5}\right.$, $\mathrm{Ta}+\mathrm{L} 1, \mathrm{~L} 1+\mathrm{L} 2)$ around the eutectic temperature calculated from (19), (20), and (22)

Fig. 6 The comparison between the calculated values from Eq. (7), (8), (17) and (18) and the measurement data of $\Delta \mathrm{G}_{\mathrm{f}}^{0}\left(\mathrm{Ta}_{2} \mathrm{O}_{5}\right)$ from the literature 